\title{
As metodologias de recém-doutores dos programas de pós-graduação em sociologia no Brasil: das disciplinas às teses
}

\author{
Marina Félix de Melo' \\ Selefe Gomes da Silva Neta ${ }^{2}$ \\ Rúbia Carmita do Nascimento ${ }^{3}$
}

\section{Resumo}

O presente artigo é resultado de uma pesquisa com recém-doutores em Sociologia de Programas de Pós-Graduação brasileiros e investiga a hipótese de que os problemas de pesquisa das teses de Sociologia não determinam os métodos a serem utilizados nos trabalhos, sendo tais métodos determinados pelas condições de competências técnicas e de formação dos pesquisadores e por dimensões relacionadas a fatores relacionais entre os atores e a vida acadêmica. Observamos a ênfase dada ao aspecto metodológico de teses, examinando a percepção e o interesse que os investigadores têm a respeito de perspectivas metodológicas diversas. Apresentamos uma análise documental das ementas das disciplinas metodológicas nos cursos de doutorado e uma análise de conteúdo realizada a partir de 35 entrevistas com recém-doutores em Sociologia. Investigamos aspectos dimensionados a questões de orientação acadêmica, relações institucionais, intercâmbios, dentre outras experiências vinculadas a processos de formação metodológica dos atores.

Palavras-chave: Teses sociológicas. Pós-graduação. Metodologia.

\footnotetext{
I Doutora em Sociologia pela UFPE/UMinho. Professora Adjunta da Universidade Federal de Alagoas

2 Bacharel em Ciências Sociais pela Universidade Federal de Alagoas

3 Graduanda em Ciências Sociais pela Universidade Federal de Alagoas
}

$((c))$ EY
Direito autoral e licença de uso: Este artigo está licenciado sob uma Licença Creative Commons. Com essa licença você pode compartilhar, adaptar, para qualquer fim, desde que atribua a autoria da obra, forneça um link para a licença, e indicar se foram feitas alterações. 


\section{Contextualização de um campo investigativo e os aspectos norteadores da pesquisa}

O presente artigo se origina na problemática mais ampla de um trabalho publicado na Revista Brasileira de Sociologia (MELO; BERNARDO; GOMES, 2018) em que se investigou como ocorre, porque ocorre e que consequências carregam as escolhas metodológicas de trabalhos acadêmicos da Sociologia brasileira. O principal objetivo percorrido na altura foi o de analisar a utilização metodológica de perspectivas qualitativa e quantitativa em trabalhos acadêmicos da Sociologia, nomeadamente teses de doutorado realizadas no Brasil, e seus respectivos autores, no triênio 20122014, a pensar não somente nos aspectos metodológicos diretamente ligados a tais teses, mas também a considerar as conjunturas de produção das pós-graduaçôes em que se inserem as investigaçôes.

De forma paralela, objetivamos: 1 . verificar os principais métodos e técnicas utilizados nas teses de Sociologia; 2. analisar as justificativas utilizadas nos trabalhos para a aplicação de determinados métodos de análise; 3. perceber se há significativa construção de novas técnicas, ou alterações nos métodos tradicionais, que caracterizem processos criativos dos pesquisadores; 4. observar a ênfase dada ao aspecto metodológico dos trabalhos; 5. realizar uma análise documental sobre as ementas das disciplinas de metodologia disponibilizadas pelos Programas de Pós-Graduação aos estudantes de doutorado; 6. examinar a percepçáo e o interesse que os investigadores têm a respeito de perspectivas metodológicas náo diretamente utilizadas em seus trabalhos de tese e; 7 . verificar se os investigadores se sentem aptos à utilização de outras metodologias, supostamente não utilizadas em seus trabalhos. Os objetivos de 01 a 04 já foram contemplados e publicados na Revista Brasileira de Sociologia (MELO; BERNARDO; GOMES, 2018). O presente texto tratará sobre os objetivos de 05 a 07 , inéditos, e que caracterizam a continuidade da investigação a partir de resultados já alcançados.

A justificativa inicial que nos impulsionou a estudar as propostas básicas das teses de Sociologia no Brasil foi a de entender o que estava sendo produzido na Sociologia brasileira contemporânea. O projeto original em que se localizam nossos dados é formado por três etapas. A primeira 
etapa é um estudo quantitativo sobre as metodologias utilizadas em 282 teses de Sociologia defendidas entre os anos 2012-2014 nos 13 Programas de Pós-Graduação em Sociologia (PPGSs) do País existentes na altura da coleta de dados. A segunda, uma análise dos conteúdos metodológicos estudados pelos pesquisadores ao longo de suas formaçóes sociológicas, contendo uma análise das ementas e estruturas metodológicas formativas dos Programas de disciplinas ministradas nos cursos de mestrado e doutorado em Sociologia no Brasil. A terceira, um estudo qualitativo com 35 entrevistas a compreender as motivaçóes patentes e latentes ao processo metodológico de pesquisa sociológica, em que são investigadas as teses da primeira etapa da investigação a partir de seus autores. A hipótese central que investigamos é de que os problemas de pesquisa das teses de Sociologia não determinam os métodos a serem utilizados nos trabalhos, sendo tais métodos determinados pelas condiçôes de competências técnicas e de formação dos pesquisadores e por dimensóes relacionadas a fatores relacionais entre os atores e a vida acadêmica.

$\mathrm{Na}$ primeira fase de pesquisa muitas teses que analisamos não citavam, ao longo das centenas de páginas, a palavra "Metodologia", bastanto teclar um comando "control F" no arquivo em PDF para verificarmos a inexistência do termo em muitos trabalhos. Não que isto significasse que não tenham considerado metodologia a partir de outra semântica, tampouco, que não a trabalhem; porém, esta informação tem um cruzamento substancial com os dados apresentados (MELO; BERNARDO; GOMES, 2018), mostrando, pelo menos, o não protagonismo das questóes metodológicas ao grosso das recentes teses de Sociologia no Brasil. Igualmente, o fato de muitas apresentarem, de acordo com nossos dados, seus sumários por uma estruturação de "teoria e campo concomitantemente", não significa que estes aspectos estejam reflexionados concatenadamente ao longo dos textos. Em muitas situaçôes, localizamos estruturas "soltas" justamente pelo aspecto plenamente notado em nossa pesquisa de que muitas teses não possuíam a apresentação de uma metodologia pontuada, dificultando a localizaçáo dos argumentos sustentados, o que inviabilizou um possível melhor acesso ao material, sobretudo por parte daqueles que náo são da área sociológica e que não tramitam pelo campo semântico aí compartilhado. Paralelamente, dizer que uma tese tem um capítulo ou subtópico 
metodológico não significa que o leitor irá nele encontrar os passos adotados na investigação do autor. Em muitas teses, encontramos reconstructos sobre o que outros autores entendem por metodologia ou por métodos e técnica; porém, sem o autor da tese em tela angular o seu trabalho ao que está referenciando de outros autores. De forma semelhante, o autor da tese, no capítulo metodológico, afirmar que realiza uma técnica de análise, como uma análise de conteúdo ou discurso, por exemplo, tampouco significa que este o faça quando chega à altura da análise dos dados, ficando a técnica de análise como uma mera citação ao longo de um trecho isolado do trabalho, sem uma aplicação explicitada. Dessa forma, para além de observaçóes feitas sobre os impactos de gênero, regiáo, nota capes, dentre outros, retrabalhamos nestas páginas a conclusão a que chegamos a partir da primeira fase da pesquisa, de análise das 289 teses, de que os aspectos metodológicos das pesquisas de doutorado analisadas apresentam-se de forma tímida e com pouca ênfase na estrutura escrita das teses de Sociologia no Brasil.

Nas segunda e terceira fases da pesquisa, nas quais nos centramos neste texto, tivemos para a segunda fase uma coleta de dados a partir das ementas das disciplinas de todos os cursos de doutorado em Sociologia do Brasil, 12 Programas na altura da coleta de dados desta etapa (2018). A recolha das informaçóes foi feita pelos sites das instituiçóes e por contatos diretos realizados com os coordenadores dos Programas quando surgiam eventuais dúvidas e ou contradiçóes a respeito do planejamento pedagógico dos cursos. Já para a terceira fase, em que tivemos como interlocutores os autores das teses de doutorado, utilizamos como técnica de recolha de informaçóes entrevistas semiestruturadas realizadas presencialmente e/ou por telefone em todo o País com autores selecionados através da técnica de bola de neve. Os dados foram tratados a partir da técnica de análise de conteúdo (BARDIN, 2011).

Totalizamos 35 entrevistas (2017-2018) e contamos com a colaboração de 19 homens e 16 mulheres. Foram 07 entrevistas realizadas com doutores formados em Programas de Pós-Graduação em Sociologia pela Universidade Federal da Paraíba (UFPB), 06 pela Universidade Federal de Pernambuco (UFPE), 05 pela Universidade Federal do Rio Grande do 
Sul (UFRGS), 03 pela Universidade Estadual do Rio de Janeiro (UERJ), 02 pela Universidade de Campinas (UNICAMP), 02 pela Universidade de Brasília (UNB), 02 pela Universidade Federal de São Carlos (UFSCar), 02 pela Universidade Federal do Paraná (UFPR), 02 pela Universidade Federal de Minas Gerais (UFMG), 02 pela Universidade de São Paulo (USP), 01 pela Universidade Federal do Ceará (UFC) e 01 pela Universidade Federal de Sergipe (UFS) ${ }^{4}$. Salientamos que as entrevistas seguiram o mesmo recorte amostral utilizado na primeira fase da investigação, com as teses, no que se refere ao Programa de Pós-Graduação. Explicamos: ainda que o Comitê de Área da Capes de Sociologia abranja os cursos de ciências sociais, planejamento e políticas públicas, políticas públicas e sociedade, Sociologia política, defesa social e mediação de conflitos e Sociologia e antropologia, tratamos apenas dos trabalhos realizados nos Programas exclusivos da Sociologia. Este recorte foi para que tivéssemos em atenção uma unidade de apoio, no caso a pretensão sociológica destes trabalhos, na escolha dos métodos e técnicas utilizados pelos pesquisadores. Embora a maioria dos autores entrevistados na terceira fase da pesquisa tenha tido teses analisadas na primeira fase (porque nesta primeira realizamos um senso com todas as teses contidas no recorte temporal proposto de 2012-2014), não realizamos nenhuma comparação entre os dados coletados nas diferentes etapas, tampouco acrescentamos ao roteiro de entrevista aspectos das teses que os próprios autores náo levantassem por si. Esta medida foi uma forma encontrada de evitarmos viés de interpretação dos dados ou prejulgamentos, bem como para anularmos discrepâncias entre os roteiros, posto que algumas teses tivessem sido analisadas, outras não, haja vista que o recorte temporal da terceira etapa foi mais amplo, incluindo doutores formados entre os anos 2012-2017.

Nesta investigação, foi importante considerar que metodologia é um conjunto de abordagens que se relaciona a aspectos ontológicos e epistêmicos amplos e que geram técnicas e processos que possibilitam aos investigadores compreender seus objetos de pesquisa. A construção destes objetos

4 Para uma melhor visualização do corpus analisado temos, por gênero, sendo M para sexo Masculino e F para sexo Feminino: UNB: OIM e OIF; UFPE: 03M e 03F; UFPB: 03M e 03F; UFC: 02M; UFS: OIF; UFRJ: 02M e 0IF; USP: 02M; UNICAMP: 02 F; UFMG: 02M; UFSCAR: 02 F; UFPR: 01 M e OIF e UFRGS: 03M $~ 02 F$. 
tende a determinar o tipo de metodologia que os investigadores utilizam para responder às hipóteses que levantam em suas pesquisas. A variedade de métodos de pesquisa é muito ampla e a metodologia de onde estes se originam é parte essencial do trabalho base de pesquisa.

Ao tratarmos sobre as produçóes acadêmicas defendidas em Programas com cursos de doutorado em Sociologia convém considerarmos os conteúdos mais gerais desta produção que nos liga aos interlocutores entrevistados. Grosso modo, ainda não categorizados, podemos ilustrar os temas dos trabalhos realizados pelos interlocutores pelas seguintes composiçôes: Sociologia dos objetos; histórias em quadrinhos; educação e modernização; classes sociais e desempenho educacional; movimentos Sociais; Raul Seixas; urbanização litorânea; consumos; modelo comunitário de universidade; economia do compartilhamento (dádivas digitais); relação entre trabalho e vida dos trabalhadores de tecnologia da informação; política habitacional; blackblocks; moradores de fazendas; conjugalidade e swing; regulação de telecomunicações; culturas jurídicas; políticas públicas; recepção dos pensamentos de Georg Lukacs e de Theodor Adorno no Brasil; imagens institucionais da polícia; movimentos sociais; migraçôes internas; juízes como figura de autoridade; mercado do etanol; religião; empreendedorismo e capital social; identidades árabes no Brasil; agenciamento artístico; políticas fiscais; responsabilidade social; associativismo; política externa brasileira com a África; telenovelas etc. Posta esta Pluralidade de objetos, categorizamos os temas das teses produzidas pelos entrevistados de acordo com os seguintes itens ${ }^{5}: 1$ - Arte e Cultura (03 entrevistados com teses nesta temática); 2- Economia e Consumo (03); 3- Criminalidade/Violências (01); 4- Educação (02); 5- Gênero e Sexualidade (01); 6- Identidades/Migração (02); 7- Juventudes e Envelhecimento (0); 8- Participação Política (02); 9- Religião (02); 10- Saúde (0);

5 As categorias utilizadas para verificação dos temas das teses dos 35 entrevistados são as mesmas usadas na primeira fase da investigação para análise dos temas das 289 teses (20/2-20/4). Na primeira fase observamos que a maioria dos trabalhos compreende a categoria "Intelectualidades/Pensamento Social/Teses Teóricas", com cerca de 15\% do quadro (40 teses). Este resultado foi divulgado (2018) em dados absolutos e, por isso, adiantamos que tais 15\% concentram-se, nomeadamente, em uma Instituição de nota Capes 7. localizada no Sudeste do Pais. Na sequência, temos a temática de "Participação Política" com 8,5\% das teses escritas; Arte e Cultura com 8,1\%; Criminalidade, com 7,7\% e Identidades e Migração, com 7,4\%. 
11- Sociologia Jurídica (02); 12- Ciência e Tecnologias (03); 13- Teses Teóricas/Intelectualidades/Pensamento Social (02); 14- Trabalho (01); 15- Ruralidades/Urbanidades/Meio Ambiente (04); 16-Instituiçóes (02); 17- Outros (05).

Para entendermos as percepçóes a respeito da metodologia e para criarmos um esquema geral sobre o que pensam e como reagem os autores a respeito de questóes metodológicas, utilizamos um roteiro de entrevista dividido nos seguintes aspectos: 1. dados gerais (caracterização geral de formação dos autores, aspectos laborais etc.); 2. disciplinas (questôes sobre suas experiências com discplinas metodológicas ao longo da formação); 3. "sanduíche" e intercâmbios formativos (questóes sobre possíveis experiências para formação acadêmica em outros centros de estudo para além dos PPGGs de origem); 4. ênfase metodológica (caracterizaçáo de aspectos metodológicos compreendidos nas teses e na formação ampla dos sociólogos). O roteiro de entrevista foi codificado na análise de conteúdo realizada a partir dos seguintes eixos: Eixo 01 "Disciplinas" (descrição - enfoque - reconhecimento/aproveitamento/interesse); Eixo 02 "Sanduíche" (motivaçáo - problemas - influências metodológicas exteriores); Eixo 03 "Ênfase metodológica" (tema da tese - metodologia utilizada - alteração metodológica no doutorado - influência da orientação - inovação metodológica - rejeiçóes metodológicas - como lida com as questóes metodológicas - ênfase metodológica da tese - ênfase metodológica geral); 04 Extras (dificuldades e facilitadores pessoais - extras relacionados aos objetivos específicos - extras imponderados).

Explicado nosso ponto de partida, iremos descrever e analisar os dados obtidos ao longo das entrevistas desta terceira fase da investigação. Entretanto, para que tivéssemos acesso ao cenário de formação metodológica dos autores, optamos por cumprir a segunda fase da investigaçáo que diz respeito ao que os PPGSs têm na estrutura curricular dos cursos de doutorado em Sociologia. Para entendermos o campo de formação de que falam os autores, realizamos uma pesquisa documental que será apresentada no tópico seguinte e que nos aproxima da análise pretendida acerca da utilização metodológica de perspectivas qualitativa e quantitativa em trabalhos acadêmicos da Sociologia. 


\section{As disciplinas metodológicas nos programas de pós-graduação em Sociologia}

Para compreensão das formas de aprendizagem das metodologias e a consequente problematização desta aprendizagem nos Programas de pós-graduação em Sociologia, analisamos as ementas das disciplinas dos cursos de mestrado e doutorado. Embora estejamos a analisar a apropriação das metodologias em cursos de doutorado, revisamos na análise das ementas também os cursos de mestrado porque constatamos, pelas entrevistas realizadas com os recém-doutores, que muitos tiveram nas disciplinas de mestrado grande influência do que utilizaram metodologicamente para as teses de doutorado. Também consideramos que alguns Programas de pós-graduaçáo têm disciplinas mais escolares nos cursos de mestrado, reduzindo o número de horas-aula para os cursos de doutorado ou mesmo criando turmas conjuntas para os dois cursos, em que alunos de mestrado e doutorado dividem o mesmo espaço pedagógico. Por estas razóes, verificamos o percurso das disciplinas metodológicas nos cursos de pós-graduação em Sociologia como um todo, recortando nossa análise documental para todas as disciplinas da nossa área de observação. Embora pareça tarefa fácil, a primeira dificuldade que nos saltou na delimitação das disciplinas que seriam verificadas foi a respeito do que consideraríamos ou não como disciplina de teor metodológico. Voltamos à delimitação de nosso objeto inicial e verificamos todas as disciplinas de cunho metodológico dos PPGSs brasileiros, desde as mais amplas, com Programas de disciplinas dedicados às questôes ontológicas, epistemológicas e de métodos de uma investigação, às disciplinas mais técnicas e específicas, a exemplo de como operar um software de análise de dados.

Os termos métodos e técnicas de pesquisa são usados geralmente de forma equivalente, embora existam diferenças entre ambos. Métodos seriam estratégias de produção de conhecimento científico, incluindo a geração e a validação de teorias. Técnicas seriam formas padronizadas de coleta e análise de dados, com a mesma finalidade, a de produzir conhecimento válido. Embora a diferença entre os dois conceitos seja porosa, o método é muito mais abrangente e se aproxima da epistemologia, contemplando estratégias gerais, enquanto que a técnica é específica e concreta [...]. Métodos clássicos seriam o Método Indutivo e o Dedutivo. (CANO, 2012, p.94). 
Cano, em publicação sobre o ensino da metodologia das ciências sociais no Brasil, faz um longo e interessante percurso sobre a história metodológica das ciências sociais e do dualismo aparente entre metodologias quantitativas e qualitativas. Criticamente, reflete sobre o ensino que considera tradicional nas ciências sociais brasileiras e afirma que existe uma excessiva ênfase nos clássicos e na erudição nos cursos de metodologia das ciências sociais em detrimento de um enfoque às questôes empíricas de investigação. "[...] o ensino da metodologia das ciências sociais no país é permeado por uma falsa oposição entre as técnicas quantitativas e qualitativas, que são elevadas à categoria de metodologias diferentes e inclusive contraditórias" (CANO, 2012, p. 94).

Neste contexto, inserimos nosso objetivo específico de realizar uma análise documental sobre as ementas das disciplinas de metodologia disponibilizadas pelos Programas de Pós-Graduação aos estudantes de doutorado. A análise de conteúdo contemplou 64 ementas de disciplinas eletivas e obrigatórias dos PPGSs das seguintes universidades: UFPE (10), UFSCar (02), UFS (05), UFC (09), UFPR (11), UFG (02), UERJ (02), UFRGS (09), UFMG (06), UNB (01), USP (01), UFPB (02) e UNICAMP (04)6.

A maioria das ementas das matérias analisadas declara que o curso tem como norte didático discussóes, apresentaçôes de seminários e análise dos trabalhos de investigação/projetos dos próprios alunos matriculados nas turmas. Outra parte é composta de matérias que têm por foco análise e discussão das principais etapas dos processos existentes em uma pesquisa como "análise de objeto", "problema”, "campo", "metodologia”, bem como demais etapas existentes na construção de um projeto de pesquisa e, consequentemente, de uma dissertação ou tese. Encontramos em parte das ementas o foco no "conhecimento de métodos e tratamento de dados da pesquisa social”, já em outras, o foco está em discussóes de princípios epistemológicos acompanhadas de aspectos teórico-metodológicos, com revisão de posturas clássicas, como já salientado por Cano (2012).

Selecionamos 64 ementas a partir dos quadros de disciplinas publicados nos websites de cada Programa de Pós-Graduação nos últimos anos (2009-2016). Em alguns casos, não encontramos as disciplinas ofertadas ou não encontramos disponíveis on-line nem no site do Programa e nem na plataforma sucupira suas respectivas ementas. Nestes casos, entramos em contato com as secretarias dos Programas e solicitamos estas informações diretamente por e-mail. 
Verificamos algumas disciplinas que variavam em nomenclatura de um PPGS a outro, mas que tinham os conteúdos de suas ementas bastante semelhantes. A nomenclatura da maioria das matérias presentes nos Programas de pós-graduação, tanto para o mestrado quando para o doutorado, era "metodologia", podendo ser "metodologias avançadas", "metodologias específicas", "metodologia de pesquisa social" ou "metodologia das ciências sociais" (13 casos encontrados). Com as matérias relacionadas a "seminários" (07), encontramos seminários de dissertação, de tese, de projeto, de pesquisa, metodológicos e avançados. Diversas disciplinas também se relacionam a métodos quantitativos (10) e qualitativos (05), com técnicas específicas para cada área.

Os PPGSs com maior número de disciplinas metodológicas analisadas foram UFPE, UFC, UFPR e UFRGS, com cerca de 09 a 11 matérias cada um. Com um número mais restrito temos UNB e USP, com apenas 01 cada. Os Programas com mais matérias obrigatórias avaliadas foram UFPE, UFMG e UFPR, variando de 05 a 07 disciplinas. Os PPGSs com mais matérias de metodologia verificadas nos cursos de doutorado foram UFC, UFPR e UFPE, com 04 a 06 disciplinas, contrastando com outras universidades que tinham em torno de 01 a 03 ementas em análise. Os Programas com mais matérias metodológicas nos cursos de mestrado foram UFRGS e UFPR, com cerca de 05 disciplinas cada. Os Programas com mais matérias eletivas no mestrado foram UFC, UFRGS, UFPR e UNICAMP, com cerca de 03 a 04 matérias. Os Programas com mais matérias eletivas no doutorado foram UNICAMP, UFPR e UFC, também com cerca de 03 a 04 disciplinas por Programa. Os PPGSs com apenas disciplinas metodológicas obrigatórias, nos quais não foram verificadas disciplinas metodológicas eletivas, foram UFS, UFMG, UFG e UFPB.

Codificamos e categorizamos as ementas analisadas em 04 divisões no que diz respeito à ênfase dos conteúdos propostos e, na sequência, verificamos o perfil das ementas por universidade, obtendo o seguinte mapeamento: disciplinas metodológicas com ementas que enfatizam questóes referentes à metodologia da ciência (UnB, USP); ementas que enfatizam a construção de projetos de pesquisa (UFSCar, UFS); que enfatizam métodos e técnicas qualitativos e quantitativos na construção das dissertaçóes ou teses (UFC, UFPR, UFG, UERJ); que enfatizam tanto a elaboração de 
projetos quanto o uso das técnicas qualitativas e quantitativas nos trabalhos acadêmicos (UFPE, UFRGS, UFMG). Salientamos que esta categorização não é exaustiva, tampouco excludente, servindo apenas como um parâmetro de verificação dos conteúdos das ementas em tela. Em nenhum caso um Programa que tenha sido categorizado em um dos aspectos por ter maior frequência de disciplinas no referido código está restrito a disciplinas dentro do código indicado.

Verificados os conteúdos das ementas como uma forma de aproximação do universo metodológico dos estudantes de doutorado em Sociologia no Brasil, buscamos entender como os recém-doutores percebiam e compreendiam as disciplinas que cursaram ao longo de suas pós-graduaçóes em Sociologia. De 35 sociólogos entrevistados, 30 afirmaram terem tido disciplinas metodológicas durante o período da tese. Os nomes destas disciplinas, conforme mencionadas pelos entrevistados, eram semelhantes. A maioria era "metodologia", podendo ser de informaçóes, avançada ou das ciências sociais, matérias específicas de metodologias e técnicas qualitativas e quantitativas, também, seminários ou projetos de tese e de epistemologia, técnicas específicas, pesquisa de campo etc. Alguns interlocutores não lembravam os nomes das disciplinas que tinham cursado, ou sequer se tinham cursado. 13 pessoas declararam que tiveram apenas 01 matéria metodológica, 07 declararam que tiveram 03 disciplinas, 05 disseram que tiveram 02 matérias e 02 pessoas falaram que tiveram 04 matérias.

Seguindo por esta fase de entrevistas, nas perguntas relacionadas ao reconhecimento das matérias, os interlocutores disseram, em maioria, que estas disciplinas eram sobre discussóes teóricas ou metodológicas, sobre a produção de projetos, construção de teses e apresentação de andamento das pesquisas (11). Alguns entrevistados falaram que as matérias eram sobre aprender ou aplicar novas ferramentas metodológicas (07); outros, lembravam que as disciplinas eram bastante amplas, não aprofundavam em nada ou eram sobre análise metodológica da teoria dos clássicos. A maioria dos entrevistados declara ter tido matérias teóricas, algumas fazendo análises metodológicas das teorias ou que estas disciplinas metodológicas serviam como um momento de apresentaçáo dos trabalhos de tese ou da metodologia destes trabalhos (08), em que se mostravam o andamento da pesquisa com a discussão dos projetos entre a turma. 
[...] o professor não tinha interesse em saber se os alunos já tinham esse conteúdo. Aprendi as fórmulas e a lógica delas e aplicava sem aprofundar o assunto. Não consegui assimilar o conteúdo. (Entrevistado $0 \mathrm{I}$ ).

Tenho a sensação que terminei o doutorado sem saber fazer pesquisa [...] não sinto que domino o campo da metodologia. (Entrevistada 02).

Sobre o aproveitamento das disciplinas, a maioria (15) declara que estas contribuíram para a construção da tese, que foram boas ou influenciaram diretamente no resultado final da investigação. Quase na mesma proporção (13), outros entrevistados explicam que tiveram um aproveitamento razoável ou baixo em relaçáo às disciplinas e apenas um entrevistado (01) nega por completo qualquer aproveitamento nas aulas de metodologia. Entretanto, ainda que com variadas percepçóes sobre o autoaproveitamento nas disciplinas, alguns entrevistados alegam que estas foram interessantes, independentemente do aprendizado metodológico, no que se refere ao conhecimento e acompanhamento dos trabalhos dos colegas de turma, fazendo com que diferentes temas de pesquisa aparecessem em pauta, os fazendo construir uma opinião crítica a respeito destes trabalhos.

Questionamos aos entrevistados o que eles consideravam haver de melhor e de pior nas matérias metodológicas cursadas. Positivamente, 11 entrevistados declararam que com as disciplinas tiveram acesso a novos conteúdos a partir da apresentação dos trabalhos em andamento dos colegas de turma. Afirmaram terem tido professores que os ensinaram sobre a delimitação e a reflexão do objeto de estudo, assim como alguns entrevistados declararam como positiva a construçáo de um novo olhar sobre os aspectos mais empíricos daquilo que entendiam como metodologia.

[...] sem essas aulas, seria impossivel construir uma tese; sem essas matérias, os trabalhos seriam filosofia social e não Sociologia científica. (Entrevistado 03).

O enfoque era preparar o projeto para ser viável de apresentação de qualificação com a instituição que dava as bolsas, para ser aprovado pela (Fundação de Amparo à Pesquisa Local). (Entrevistada 04).

Sobre o que havia de pior nestas matérias durante o doutorado, tivemos alguns relatos sobre a falta de incentivo e aprofundamento para questóes metodológicas pelos professores (04); ter que comentar e discutir 
temas distantes referentes aos trabalhos dos colegas (04); falta de aprofundamento dos conteúdos com pouca abordagem teórica e metodológica ou queixas sobre uma estrutura muito clássica e teórica das disciplinas para o período de feitura da tese (n).

As disciplinas dialogavam com a pesquisa de doutorado. Até certo momento houve aproximação, mas também em alguns momentos deixavam e aberto. Eram leituras às vezes mais amplas. (Entrevistado 05).

De pior era a falta de laboratório, de utilizar outras metodologias, como programas quantitativos. E o de melhor era a professora. (Entrevistada 06).

O pior era não serem tão aprofundados os conteúdos. Acho que um doutorado de cinco anos com mais ênfase nas disciplinas seria ótimo. O de bom é que dá uma consciência da construção de conhecimento, aprender sobre o científico e o objetivo. (Entrevistada 07).

A prática é o pior. Elas são teóricas, não existe prática de pesquisa, a gente lê textos e conversa entre eles. Existe um déficit na prática quanti. [...] 0 método é muito renegado na academia mesmo sendo bastante discutido. Tratam o método teoricamente e não tem práxis [...]. A questão do método no exterior é relacionada ao dialético, ao compreensivo, e aqui no Brasil relacionam apenas com quanti e quali. Ee isso é um problema. (Entrevistado 08).

Vinte e um (21) entrevistados declararam terem tido matérias metodológicas no campo das ciências sociais durante o curso de mestrado. Desses entrevistados, menos da metade (07) relatou que essas matérias os importaram de alguma forma, sobretudo na construção do projeto de seleção de doutorado consoante ao desenvolvimento das técnicas metodológicas. A maioria (17) declara que as matérias no mestrado não ajudaram para o período do doutorado porque eram genéricas e não tinham o aprofundamento necessário e explicaram que tiveram pouca ou nenhuma influência das disciplinas metodológicas do mestrado para a tese de doutorado em si. Um deles mencionou: "Tive essa matéria no mestrado, mas foi bem ruim, bem "colegial" e inútil. A matéria do mestrado foi uma perda de tempo" (Entrevistado 09).

A partir das entrevistas analisadas conjuntamente às ementas das disciplinas corroboramos com o que Errandonea ([s. d.]) chama de processo pós moderno de degradação empírica. $\mathrm{O}$ autor argentino alerta que disciplinas metodológicas não poderiam cair ao desconhecimento de investigaçóes 
nitidamente empíricas, especialmente na Sociologia, em que o modo de produção científico possui larga história de busca por legitimação diante de outras áreas das ciências ditas duras. Errandonea ([s. d.], p. 3) destaca que estas disciplinas devem ser centrais a respeito da diversificaçáo e inovaçáo de técnicas que constituem o enriquecimento da capacidade metodológica de um campo de estudo. As inovaçôes de objetos sociológicos pedem, no que estendemos a argumentação da autor, o desafio de inovação também das disciplinas necessárias ao suporte teórico-empírico das investigaçóes de doutorado; afinal: "La innovación de técnicas metodológicas no tiene incompatibilidad alguna con el rigor cientifico” (ERRANDONEA, [s. d.], p. 3).

Os ajustes entre as diversas possibilidades metodológicas no campo das ciências sociais, as disciplinas metodológicas dos Programas e as metodologias contidas nas teses de doutorado em Sociologia no Brasil são espaços de um denso campo acadêmico. Passaremos para o tópico seguinte que busca entender como os doutores que investigamos carregam, das disciplinas cursadas até as teses defendidas, as metodologias que compreendem para seus objetos e problemas de pesquisa.

\section{As metodologias nas teses dos doutorandos em Sociologia}

Na primeira fase da investigação, em que analisamos as teses de doutorado brasileiras do período de 2012-2014, elaboramos um retrato dos conteúdos metodológicos presentes nestas teses de Sociologia do País (MELO; BERNARDO; GOMES, 2018). Todavia, somente na terceira etapa de investigação que tivemos acesso aos autores destes materiais por meio de entrevistas semiestruturadas. Nestas, pudemos entender as lógicas de produçáo metodológicas a partir das falas dos pesquisadores, conectando suas produçóes a contextos diversos que envolvem o universo acadêmico destes atores. Examinamos a percepção e o interesse que os investigadores têm a respeito de perspectivas metodológicas não diretamente utilizadas em seus trabalhos de tese e verificamos se estes se sentem aptos à utilização de outras metodologias, supostamente não utilizadas em seus trabalhos.

Entre perspectivas qualitativas e quantitativas de análise social, as principais metodologias e técnicas citadas como utilização e reconhecidas 
pelos nossos interlocutores foram etnografia; entrevistas; análises de conteúdo, análise de redes; uso de software Nvivo; técnicas estatísticas; levantamento bibliográfico; dados secundários; trabalho de campo; entrevistas qualitativas; traceabilidade digital; entrevistas semiestruturadas presenciais e on-line; metáfora de sistemas; observação participante; diário de campo; síntese de elementos teóricos com observações diretas; construção de tipos ideais; metodologia diacrônica sistemática; história de vida; análise de discurso crítico; pesquisa in loco; observação não participante. Este conjunto que reúne técnicas de recolha de informaçóes e técnicas de análise de dados foi formado a partir da fala dos autores quando perguntávamos, grosso modo, qual a metodologia utilizada em suas teses. O conjunto acima já nos indica que a palavra metodologia pode se referir, para estes interlocutores, a aspectos distintos das etapas de pesquisa e que não existe um traço marcado entre o conjunto de entrevistados que os reúna sobre o que seja metodologia, se uma técnica, se uma aplicação, chegando a encontrar informaçóes que variam de "entrevistas" a "análise de discurso" em uma mesma questão.

Sem grandes surpresas, a perspectiva metodológica mais utilizada pelos 35 interlocutores é a qualitativa, verificada em quase todos os casos, ainda que na utilização de algumas metodologias mistas declaradas pelos entrevistados (06). Somente um pesquisador adotou metodologia quantitativa na abordagem da tese (01). Alguns entrevistados destacaram muita dificuldade a respeito de iniciarem um trabalho de campo, de "entrarem" no campo da pesquisa, inviabilizando os processos de coleta de dados de algumas destas teses.

No que diz respeito a alteraçóes metodológicas no percurso da pesquisa, a maioria fez algum tipo de modificação (19). Um dos entrevistados, que fez alteraçóes metodológicas no modelo da tese ao longo do curso de doutorado, explica a necessidade de alteraçóes quando, por exemplo, não foi possível aplicar os questionários à comunidade pretendida. Grosso modo, as alteraçóes foram atribuídas pelos entrevistados mais as dificuldades encontradas para a coleta de dados inicialmente pretendida do que, propriamente, à formação que tiveram nas disciplinas metodológicas, ainda que alguns pesquisadores atribuam algumas de suas mudanças às leituras realizadas ao longo de todo o processo de doutorado, incluindo, por suposto, as leituras de tais disciplinas de que tratamos no tópico anterior. 
Além de alteraçôes, buscamos compreender se autores inovavam metodologicamente em suas teses, bem como o que entendiam por inovação, posto não ser esta uma categoria consensual em campo. A maioria responde que não fez nenhum tipo de inovação metodológica, que apenas seguia o que era "clássico" ou já disponível em termos técnicos como instrumentos de pesquisa. Alguns interlocutores, por outro lado, consideravam-se inovadores sob tais aspectos na medida em que propuseram um método, embora já existente na literatura, inédito para análise de um determinado tipo de objeto. Quando aprofundamos os questionamentos de maneira a especificar o que consideravam inovaçóes, como aplicavam os métodos, muitos náo desenvolviam uma resposta mais detalhada/alongada para a pergunta, muitas vezes por não se lembrarem de certas características que compunham o escopo da tese defendida. Outros autores consideram que inovaram metodologicamente criando no campo acadêmico um modelo diferenciado de trabalhar métodos já populares na Sociologia, mesclando técnicas já conhecidas. Estratificando as informaçóes por sexo, percebemos que dos 19 homens entrevistados, 13 afirmaram que, de certa forma, fizeram alguma inovação metodológica. Das 16 mulheres entrevistadas, apenas 07 reconhecem que realizaram algum tipo de inovação metodológica.

$\mathrm{Na}$ tentativa de localizarmos as disponibilidades metodológicas dos agentes entrevistados, verificamos se estes reconheciam terem algum tipo de rejeição a algum tipo de método ou técnica. Encontramos entrevistados que não se propunham a trabalhar com entrevistas, outros que disseram não ter rejeição, mas que não trabalhariam com metodologias quantitativas por terem pouca afinidade com este modelo de pesquisa etc.

[...] o sociólogo deve usar qualquer método e qualquer técnica que ajude a responder o problema de pesquisa. Sem nenhum preconceito metodológico. (Entrevistado II).

Nunca utilizarei observação participante, pouco provável na estrutura acadêmica brasileira, mais provável para os europeus no século XX. (Entrevistado 12).

Em 09 entrevistas encontramos relatos de rejeição ou dificuldade com os seguintes métodos ou técnicas: materialismo histórico, observação participante, pesquisa participante e análise de conteúdo. Em 08 entrevistas encontramos rejeiçóes ou pouco conhecimento dos interlocutores com 
metodologias de tipo quantitativas. Destes 17 respondentes que se mostram resistentes à utilização de alguma ou algumas metodologias, 12 são homens e 05, mulheres. Por outro lado, quase metade dos entrevistados (18) afirma não ter resistências ou rejeiçóes; entretanto, alguns destes salientam as limitações de formação que têm a respeito, principalmente, das metodologias de perspectivas quantitativas.

Após este esboço geral sobre as metodologias das teses dos autores, explicadas por eles mesmos em um momento posterior ao da defesa e longe de qualquer tipo de verificação sobre a adequação ou não de tais métodos aos trabalhos em discussão, confirmamos a investigação que realizamos sobre as 289 teses a respeito das principais metodologias utilizadas. $\mathrm{Na}$ fase em que analisamos as teses em si, encontramos $87 \%$ de teses escritas a partir da metodologia qualitativa, 3,5\% quantitativa e 4,6\% mista ${ }^{7}$. Todavia, perceber que o campo da Sociologia brasileira se baseia na perspectiva qualitativa de investigação não é nenhuma novidade. Muitos outros trabalhos, a exemplo de Rojas e Martínez (2003) verificam esta tendência mundial, ainda que com modificaçôes sobretudo nos países anglo-saxôes desde a Escola de Chicago. O que estas entrevistas apresentadas buscaram trazer foi uma reflexão dos autores sobre tais aspectos de problematização metodológica de suas teses. Verificar certo incômodo em algumas falas sobre a possibilidade de trabalhar com outro arsenal metodológico ou certa apatia em relação a outras técnicas nos conecta à apresentação que estes mesmos interlocutores fazem sobre as disciplinas que tiveram na graduação. Longe de uma análise simplista de responsabilização, ou de uma conclusão causal imediata de que seriam as disciplinas responsáveis pela não disponibilidade de quase metade dos autores a trabalharem com outras metodologias que não as usadas em suas teses, verificamos outras dimensões analíticas que

7 A principal perspectiva metodológica utilizada, como já suposta, é a qualitativa de análise, com cerca de 87\% de teses. Em seguida, temos 3,5\% de teses em que predomina a análise quantitativa e 4,3\% construidas a partir de uma metodologia mista. Menos de $2 \%$ dos casos apresentaram como técnica principal a aplicação de uma perspectiva qualitativa com pouca introdução quantitativa, ou o inverso (3\% missing). Igualmente, nota-se que cerca de 39\% das pesquisas utilizam dados primários como principal recurso de recolha de informações, contra $32 \%$ de teses realizadas a partir de dados recolhidos exclusivamente de fontes secundárias. As investigações ancoradas por recolha mista, com dados primários e secundários, compreendem $14 \%$ da amostra, assim como 15\% são realizadas por teses teóricas ou que não apresentam tais informações diretamente aos leitores (MELO; BERNARDO; GOMES, 2018, p. 64). 
nos ajudam a compreender pela presente análise de conteúdo a relação dos autores com suas metodologias de trabalho.

\section{O papel da orientação docente e das experiências de intercâmbio na construção de metodologias em teses sociológicas}

nas entrevistas realizadas verificamos a trajetória dos atores a partir de dois grupos: os que tiveram experiência de intercâmbio no Brasil e/ou no exterior para desenvolvimento da tese, seja este em modelo de doutorado sanduíche, cotutela ou experiências ocorridas em outras universidades fora da universidade de origem do então doutorando, e dos que realizaram o doutorado exclusivamente na universidade de origem. Nestes dois grupos, procuramos entender um pouco sobre as relaçôes de orientação e as influências que estas pudessem ter a respeito dos caminhos metodológicos das teses, com os orientadores das universidades de origem e com, quando o caso, também com os orientadores de intercâmbio.

Dos 35 entrevistados, 14 tiveram experiência de doutorado sanduíche. Os países de intercâmbio mais citados foram Portugal (04), França (04), Inglaterra (02), Alemanha (01) e Bélgica (01). Além disso, 02 estudantes fizeram intercâmbio dentro do País, em universidades do sudeste. Os PPGSs que mais aparecem com estudantes com experiência de doutorado sanduíche, em nossa amostra, são UFRGS, UFPE, UNICAMP, UERJ, UFSCAR, UFS, USP e UFPR.

As motivações apresentadas para estes então doutorandos irem ou não para os intercâmbios foram das mais diversas. Dos que não tiveram a experiência, encontramos justificativas agrupadas em situaçóes como: estavam trabalhando concomitantemente ao curso de doutorado; alegavam ter as referências bibliográficas de que precisavam para a tese no Brasil; preocupaçóes com o tempo de defesa da tese caso realizassem um intercâmbio; falta de bolsas da Capes e de outras instituiçóes; Programa de pós-graduação de origem com nota capes baixa, inviabilizando o pedido de bolsa no exterior; falta de domínio de línguas estrangeiras; razões familiares, pessoais. Dos 07 interlocutores que não fizeram intercâmbio por estarem empregados, com atividades laborais muitas vezes concursadas, 05 eram homens e 02 , mulheres. 
Não fiz por questões pessoais. E o tema era muito bem trabalhado no Brasil. Meu orientador é uma das referências na área. Tive contato com os pesquisadores e, por isso, não tive interesse. (Entrevistado 0I).

Fiz sanduiche informal (no Brasil). Tentei fora, mas o projeto não foi aprovado pelo CNPQ. (Entrevistada 07).

Não cheguei a cogitar. O tema era especifico do Brasil; então, não vi necessidade. (Entrevistada 13).

Não fiz o sanduiche porque não tinha verba. O conceito capes da universidade estava muito baixo na época. Além disso, fiz vários concursos públicos, mudei de Estado, me movi bastante em função laboral. (Entrevistado 14).

Fiz contato com um professor na França, mas acabei não fazendo. Falta de bolsas, transição do governo Dilma, questão da língua estrangeira também [...] impossibilitou o doutorado sanduiche. (Entrevistado 05).

Cogitei, mas por questões burocráticas. Na época, mudou o edital do doutorado sanduíche e ia ficar muito apertado para ir e voltar a tempo. (Entrevistado 15).

No doutorado, eu achei que não ia dar conta de todos os prazos. Quando procurei, não tinha mais bolsa. (Entrevistada 04).

Cogitei a ideia, mas não fiz. As questões financeiras não eram favoráveis, vi que o sonho estava muito distante. Um estudante pobre, periférico, a bolsa é insuficiente; então, isso impediu que realizasse esse sonho. (Entrevistado 16).

Consegui a bolsa, mas depois a CAPES congelou os fundos. (Entrevistada 17).

A Capes extinguiu as bolsas do doutorado sanduiche justo quando eu ia. (Entrevistado 18).

As motivações para as pessoas fazerem o intercâmbio foram pouco justificadas. Uma das entrevistadas disse ter feito o intercâmbio para poupar dinheiro para depois completar a pesquisa no Brasil. Outros falaram que construíram a metodologia no exterior ou avançaram nos estudos metodológicos durante o intercâmbio. Os que realizaram o intercâmbio no Brasil disseram que as razóes foram para manterem suas atividades laborais.

Sobre as experiências de orientação que os entrevistados tiveram durante o intercâmbio, alguns disseram não terem sofrido relevante influência 
metodológica na universidade de destino durante o período do intercâmbio ou que os orientadores da universidade de origem e da universidade de destino tinham lógicas teóricas ou metodológicas completamente diferentes, sendo o orientador brasileiro "mais teórico" e o do exterior, "mais empirista". Entretanto, salvo estes casos mais isolados, a maioria afirma que os dois orientadores, o brasileiro e o do exterior, tinham a mesma lógica metodológica, seguindo um esquema de orientaçóes na mesma linha nas duas universidades.

As técnicas utilizadas pelo orientador estrangeiro eram mais abrangentes comparadas com o orientador brasileiro. (Entrevistada 19).

Não teve influência no sanduiche na (Universidade) sobre método, só em termos epistemológicos. (Entrevistada 21).

Uma constatação é que no Brasil tem uma carência muito grande nas metodologias quantitativas. (Entrevistado 22).

Tenho uma escrita muito enviesada e lá no sanduiche meu orientador me cobrava muito. Essa preocupação de não enviesar era muito forte lá. (Entrevistada 23).

Sobre a orientação no Brasil, ou seja, considerando as 35 entrevistas, independentemente das experiências em outras universidades fora das de origem, perguntamos aos entrevistados se as metodologias utilizadas nas teses eram semelhantes às metodologias costumeiramente tratadas nas pesquisas realizadas pelos orientadores. Tivemos 24 interlocutores que responderam que sim e 11 que responderam que náo, que aplicaram, em suas teses, metodologias diferentes das utilizadas pelo orientador. Quando restringíamos os questionamentos de maneira a nos aproximar das influências que os autores tiveram a respeito da metodologia e de seus orientadores, percebemos que 20 entrevistados, ou seja, mais da metade, entrevistados declaram ter tido influências metodológicas dos orientadores. Por outro lado, 15 dos 35 entrevistados alegam que não tiveram influência metodológica de seus orientadores. As falas a respeito da relação orientação-metodologia são das mais diversas, desde entrevistados que explicam ter metodologias bem parecidas com o professor, até pessoas que não sabiam o que o orientador produzia, tampouco como articulava questóes teóricas e metodológicas em seus trabalhos. Curiosamente, estas falas aparecem com maior frequência entre as mulheres. 
Eu não sei o que ele fazia. (Entrevistada 02).

Não tive influência. Meu orientador nunca falou de método. (Entrevistada 07).

Sim, utilizei de uma metodologia que ela utilizava. Mas tive muita dificuldade com a orientação, porque ele utilizava de modo bastante tradicional e eu utilizei de maneira mais "aberta". (Entrevistada 26).

Não, meu orientador é teórico, nunca entrevistou ninguém. (Entrevistada 17).

O orientador filósofo (do intercâmbio) sempre questionou o campo na pesquisa. Meu orientador do Brasil olhava meu trabalho e só "dava ok", não discutia. Discutia mais com meus amigos sobre campo porque parecia que sabiam mais. Ele só assinava as cartas para fazer as entrevistas. (Entrevistada 25).

O Entrevistado 08 faz uma crítica ao modo como a Sociologia brasileira trata metodologia. Ele explica que o método estudado fora do País é relacionado ao dialético, ao compreensivo, e que no Brasil a metodologia é apenas relacionada à diferenciação entre quantitativo e qualitativo. "Isso é um problema, se o sociólogo relaciona a teoria e a prática de pesquisa, poderá usar qualquer técnica. A prática é mais fácil do que grandes elaboraçóes teóricas, é mais simples na prática" (Entrevistado 08). Vimos nas entrevistas, conjuntamente com dados quantitativos da primeira etapa da pesquisa, que o acesso ao intercâmbio varia, dentre outras razóes, de acordo com o Programa em que está matriculado o estudante ${ }^{8}$. Este acesso possibilita não somente experiências mais abrangentes em culturas acadêmicas distintas, mas também, e sobretudo, uma experiência de orientaçáo (ou coorientação) para além da recebida na universidade de origem. A orientação e sua consequente influência nos aspectos metodológicos de um trabalho,

8 Sobre os estudantes intercambistas de 287 teses analisadas, temos 86 teses que contam com esta experiência e 187 que não contam. Verificamos que existe uma correlação positiva moderada de 0,35 e estatisticamente significativa entre o "sanduiche", geralmente fora do País, e o PPGS de onde é escrita a tese. Por dados brutos, os Programas que mais contam com o intercâmbio doutoral são: USP. UnB e Unicamp. Em outro extrato, localizam-se UERJ, UFSCAr, UFPE e UFRGS. Os PPGSs das universidades que menos apresentam "sanduiche" são UFG. UFPB, UFC, UFPR. UFS e UFMG. Postas as universidades, confirmamos por consequência uma relação entre região e intercâmbio. Nas regiões do País onde se concentram as notas capes dos PPGSs mais altas, concentram-se também as experiências de intercâmbio. Esta relação de que falamos tem força de 0,30, apresentando-se como uma correlação moderada, e é estatisticamente significativa (MELO; BERNARDO; GOMES, 2018, p. 67-68). 
seja dentro ou fora do País, é um objeto ainda pouco pesquisado, mas de grande relevância para entendermos a construção metodológica das teses dos sujeitos pesquisados.

Viana e Veiga (2010) discutem sobre as vozes de orientandos e orientadores sobre as contribuiçóes e fragilidades de ambos para o êxito da produção acadêmica, revelando que nem sempre a forma como professor e aluno se apresentam um ao outro corresponde à identificação pretendida pelos sujeitos. Ferreira, Furtado e Silveira (2009), na mesma linha, pesquisam a relação orientador-orientando como constitutiva de um acompanhamento muitas vezes permeado de proximidade, ainda que o grau desta proximidade (ou repulsa) varie. Segundo os autores, o nível de autonomia do estudante, autonomia esta construída de relaçóes anteriores com o mundo da investigação, é determinante na forma de atuação do orientador, que poderá ser mais ou menos intensa, frequente ou diversificada. Por outro lado, o estado de "disponibilidade" do orientador é fundamental nesta relação. Concluem que os aspectos que interferem nesta relação sejam: “[...] professores despreparados para a atividade de orientação; excesso de alunos orientandos; carência de orientadores com tempo e disponibilidade, relaçóes autocráticas, expectativas irrealistas das partes; dependência excessiva; barreiras culturais e competição entre orientador e orientando" (FERREIRA; FURTADO; SILVEIRA, 2009).

Filho e Martins (2006) investigaram as relaçóes orientador-orientando na pós-graduação no objetivo de discutir tal relação e suas influências na produção de teses e dissertações nos Programas de Pós-Graduação em Contabilidade. Indicam como resultado que, no processo de escolha de orientação, os orientadores valorizam mais características técnicas dos estudantes, já os orientandos se atêm à valorização de características afetivas e pessoais dos professores. Também afirmam que "[...] a atividade de orientação qualifica os orientandos para a autoria e que muitos problemas surgidos durante o processo de construçáo do trabalho estariam ligados à relação orientador-orientando" (FILHO; MARTINS, 2006, [s. p.]). Em estudo mais recente, Machado, Tonin e Clemente (2018) identificam e comparam as características ideias do orientador e do orientando na pós-graduação, também na área de contabilidade. Em parte contradizendo as conclusões de Filho e Martins (2006), os autores não verificam diferenças 
estatisticamente significativas a respeito do que esperam os orientandos em relação aos orientadores, e vice-versa.

Os dados revelam que as principais características do orientador ideal, na percepção de professores e alunos, em ordem de importância, dizem respeito ao orientador: ( I ) ético, honesto e justo; (2) acessível e disponível; (3) competente, eficiente e reparado; (4) desafiador, encorajador, incentivador e motivador; (5) educado e respeitoso e (6) comprometido, dedicado e esforçado. Os testes de correlação confirmaram que as características que os orientandos (alunos) consideram desejáveis nos orientadores não diferem significativamente das características que os orientadores (professores) consideram desejáveis para si mesmos, e a similaridade no julgamento entre ambos permanece ainda que o aluno nunca tenha desenvolvido a atividade de orientação. (MACHADO; TONIN; CLEMENTE, 2018, p. 45).

Em "A Dissertação de Mestrado: um Estudo sobre as Interaçôes entre o Orientador e o Orientando com Base em Incidentes Críticos”, Rodrigues Jr., Fleith e Alves (1993, p. 461) identificam que:

[...] os sujeitos do primeiro grupo (Ciências Exatas) atribuíram as dificuldades de condução da dissertação a aspectos de conteúdo e de como este é "trabalhado" pelo orientador durante o processo de orientação. Em contrapartida, os sujeitos da área de Humanas atribuíram a si dificuldades no desenvolvimento da dissertação, sem responsabilizar o orientador.

As pesquisas mencionadas delimitam por objeto de estudo as relaçôes sociais/acadêmicas no processo de orientação da pós-graduação, entretanto, náo especificam a questáo metodológica nessa relaçáo, seja em uma relação de orientação mais técnica ou mais personalizada. Ainda que esta relação não seja nosso objeto de investigação, ela se conecta com o processo de escolhas e de aplicação metodológica na Sociologia, para além das disciplinas das quais já versamos. Seguimos a proposta publicada em um recente estudo de Nobrega (2018), em que a autora propóe estreitar a relação entre pesquisa, ensino e orientação. Em verdade, a autora vai mais longe, sugerindo a necessidade de cursos de formação específica para orientadores; porém, nos deteremos à análise do tripé "pesquisa, ensino e orientaçáo", levantado por ela, para verificarmos como essas dimensóes se apresentam aos recém-doutores em Sociologia do Brasil. Consideramos os percursos e as trajetórias que envolvem relaçóes sociais e questóes pessoais para além das previstas na lógica de construção técnica de uma tese e de sua respectiva metodologia. 


\section{Processos pessoais: de doutorando a recém-doutor}

Nas entrevistas realizadas com os recém-doutores, conferimos como estes lidam com a metodologia em prováveis campos laborais, especialmente aos casos de entrevistados que são professores, ou mesmo professores de metodologia. Alguns entrevistados nunca chegaram a lecionar (13); porém, os que já ministraram disciplinas metodológicas (22), independentemente do nível (ensino médio, superior, pós-graduação), tendem a apresentar a metodologia de autores e, na sequência, passam à abordagem de técnicas. Muitos interlocutores que compartilham esta experiência docente nos contam que as discussões sobre "o que é ciência" são, geralmente, parte da entrada das discussóes subsequentes e que têm uma didática elaborada para aulas expositivas, apresentação de exemplos e desenvolvimento de pesquisa com os alunos; outros, afirmam que operam didaticamente trazendo diversas tendências metodológicas às salas de aula.

A respeito de possíveis dificuldades pessoais ou estímulos, facilitadores, no processo de construção das teses, os entrevistados apontam dificuldades com a saúde como principal empecilho no percurso do doutorado: transtornos de ansiedade; nervosismo; cansaço excessivo; estresse; desgaste; depressão; isolamento/solidão e aversão à tese aparecem com frequência nos relatos. Alguns entrevistados reforçam a dificuldade de, nas condiçóes de saúde acima, entregarem o trabalho no prazo estipulado. A angústia da pressão para a defesa da tese também se materializa no fim do recebimento da bolsa e não empregabilidade imediata. Ainda sobre as bolsas, alguns entrevistados explicam que os valores recebidos pelas agências de fomento eram inflacionados e insuficientes para a realização da pesquisa. Entre os entrevistados, 12 declararam terem desenvolvido problemas de saúde e que adoeceram em decorrência do processo de doutorado.

O entrevistado 27 teve transtorno de ansiedade por causa da tese e explica que, por isso, demorou 07 anos e meio para defendê-la. A Entrevistada 07 relatou que teve dificuldades no campo e que o processo do doutorado foi muito solitário. O Entrevistado 09 contou ter tido um transtorno de ansiedade severo que se transformou em uma depressão e consequente aversão à tese. Entrou no PPGS em 2009, foi desligado em 2014, mas 
reingressou ao Programa em 2016 e defendeu em 2017, ou seja, 08 anos perdurou seu curso de doutorado. A Entrevistada 04 também apresentou ansiedade e problemas na fase de escrita da tese. Procurou ajuda na acupuntura pela dificuldade emocional de continuar o trabalho.

Outros entrevistados relatam variados tipos de problemas que não são diretamente associados, em suas falas, à saúde. A entrevistada 28 diz que a maior dificuldade enfrentada foi relacionada às demandas domésticas diárias, com casa e filhos. Já os Entrevistados 08, 25 e 26 são enfáticos ao apontarem o processo de orientação como dificultadores do andamento do doutorado. "Parecia que ela (orientadora) queria um trabalho a cara dela e não a minha" (Entrevistada 26). A entrevistada 25 relatou muita dificuldade na orientação, bem como a falta de aprofundamento metodológico em seu PPGS. Diz que foi excluída de um grupo em que se discutia o andamento de projetos e que teve também grande dificuldade no processo seletivo para o curso de doutorado, bem como para receber uma bolsa.

Eu não tive bolsa, porque não era de lá. Vinha da (Universidade X) e não sabia o esquema. Existem lá homens que tiveram bolsa e ainda não defenderam a tese! Essa é minha crítica a (Universidade X)! Peguei a bolsa sanduiche no auge do Ciências sem Fronteiras, minha estratégia era ir e juntar dinheiro para voltar e terminar. Procurei outros professores para fazer um diálogo, e ninguém nunca tem tempo; mas, na hora da banca, todo mundo exige diversas coisas [...]. Os homens foram assim: um não tinha projeto, outro teve bolsa durante todo o tempo e ainda não defendeu. Vi que quem fez o doutorado sanduiche foram as meninas e todas fizeram campo [...]. Repare no caráter elitista da coisa, da briga dos grupos. E não passei na (Universidade Y) [...] Uma amiga que pesquisava algo parecido com o meu trabalho começou a procurar coorientaria e ele (orientador) disse que, se ela procurasse, não ia mais orientar e desliga-lá do Programa. Então, quando essa professora disse que me coorientaria, eu nem disse a ele (mesmo orientador). Método tem a ver com a orientação também. Ele (orientador) pode mostrar mais ferramentas para usar no campo. (Entrevistada 25).

Alguns relatos foram sobre as dificuldades na escrita da tese por diversos fatores, como choques ideológicos e dificuldades no campo. Muitos disseram ter pensado em desistir da tese, que ela representava uma angústia.

No que diz respeito à atual atividade laboral dos entrevistados, encontramos 12 que atualmente são professores universitários. Destes, 09 são homens e 03 mulheres. 05 entrevistadas estão realizando pós-doutorado. 
02 entrevistadas desenvolvem investigação em institutos de pesquisa. 05 entrevistadas estão trabalhando fora da área acadêmica. 04 entrevistados homens se declaram desempregados e, os demais (07), não declararam nenhuma atividade laboral na altura da entrevista.

Estes dados marcam um campo inexoravelmente interessante aos estudos sobre gênero, relações de orientação e saúde na academia. Por razôes de delimitação, este artigo não tratará mais a fundo de tais pontos; entretanto, convém ressaltarmos algumas publicaçóes atuais que enfocam estas dimensôes no campo acadêmico.

Recentemente, na "Nature Biotechnology", foi publicada uma pesquisa que assegura que os doutorandos são seis vezes mais propensos a desenvolverem ansiedade ou depressão em comparação à população geral. Ao estudar diferentes áreas, o estudo registra que 39\% dos doutorandos se encontram em um perfil de depressáo moderada ou severa, frente aos 6\% da população geral. Quando estratifica os dados entre os gêneros masculino e feminino, conclui que as mulheres têm $27 \%$ a mais de chances de sofrerem problemas psiquiátricos em relação aos homens. (VANDERFORD apud BARRECHEGUREN, 2018).

Em 2017, foi realizada uma pesquisa, pela Globonews, em que se constatou que o número de professores afastados por transtornos mentais ou comportamentais nas escolas estaduais de Sáo Paulo teve um aumento de aproximadamente $100 \%$ de 2015 para 2016, pulando de mais de 25 mil ocorrências para mais de 50 mil (ARCOVERDE et al., 2018). Esses números representam mais de $37 \%$ das causas de afastamentos, incluindo-se aí as mais diversas causas de licenças médicas. Além do transtorno em si, existe o fato de o transtorno ter sido notificado para que virasse um dado de investigaçáo, pelo que desconhecemos as razóes do aumento de notificaçóes. Todavia, ainda assim, os números absolutos em que se enquadram as informaçóes são preocupantes no que concerne à saúde pública de parte integrante da educação brasileira.

Oliveira (2018) publicou "Depressão na universidade: como a pressão acadêmica afeta a saúde mental”, mostrando que os números sobre depressão na academia se agravam na medida em que o nível do diploma também avança. "Segundo a Associação Nacional dos Dirigentes das 
Instituições Federais de Ensino Superior, 15\% dos estudantes de nível superior apresentam algum quadro depressivo. A média geral de quem não passa pelos dissabores da vida acadêmica é de 4\%" (OLIVEIRA, 2018). A Universidade de São Paulo aponta que 33\% dos estudantes de pós-graduação sentem-se deprimidos ou ansiosos (OLIVEIRA, 2018). "É uma combinação de fatores. Escolher determinados mundos que são muito competitivos e exigentes, muito comparativos, é difícil para quem não tem uma estrutura psicológica que aguente pressão." (GOLDENBERG apud OLIVEIRA, 2018).

Quando versamos sobre gênero e universidade, na mesma toada de preocupaçôes com saúde, relaçôes sociais e de orientação, integração universitária, produção acadêmica etc., constatamos uma revisão de diversos estudos contemporâneos que conversam com nossos dados. Pelas limitaçóes deste artigo já mencionadas, não entraremos neste interessante debate no momento, e nos limitaremos às questôes metodológicas das teses destes agentes.

\section{Conclusão}

A realização deste trabalho se justificou, em primeiro plano, não como um estudo sociológico propriamente dito, mas, sim, como um estudo para a Sociologia. A conexão entre as dimensóes de um estudo sociológico e de um estudo para a Sociologia será desenvolvida, na prática, pelas utilizaçóes empíricas propostas no trabalho. Logo, partimos do pressuposto de que as questóes de metodologia e de métodos e técnicas são imprescindíveis à operacionalização da "imaginação sociológica" (MILLS, 1975) proposta nos diversos temas de pesquisa tocados pela Sociologia contemporânea.

Notamos ao longo da investigação certa "tensão" dos interlocutores quando o tema de debate alcançava as questóes de métodos de suas teses. Desde os clássicos, o método e as questôes que diziam respeito à objetividade das ciências sociais têm terreno contraditório no campo da Sociologia, haja vista o surgimento da disciplina plantada pelo positivismo. Os pressupostos hermenêuticos e historicistas também nos deixam marcas que, ao mesmo tempo em que nos aproximam das questóes de que tratam a Sociologia, nos trazem mais questionamentos sobre como operá-las, isto é, sobre como conhecer a realidade, tanto nos moldes mais abstratos, 
metodológicos em si, quanto nas necessidades mais braçais, manuais e operativas das investigaçóes, de suas técnicas. A priori, os métodos qualitativos têm grande marca na Sociologia, que traz para si estudantes "fugidos" das exatas. Esta é a voz do senso comum acadêmico nos corredores dos departamentos de humanidades. Todavia, tencionamos apreender em que medida essa voz se propaga, e se realmente corresponde aos quadros mais recentes de que dispomos.

As escolhas metodológicas e, mais precisamente, os métodos e as técnicas adotados no trabalho sociológico, tendem a aparecer como pontos nebulosos desde o momento de elaboração dos projetos de tese. Quando um pesquisador se candidata a um curso de doutorado costuma apresentar, durante o processo seletivo, um pré-projeto em que elenca, de maneira muitas vezes vaga, o que quer fazer. Neste momento, em que uma banca examinadora verifica a maturidade do candidato ao curso, joga-se luz no seu problema de pesquisa e em algumas questóes metodológicas en pasant. Depois de aprovado, o candidato com seu projeto começa a abrir um leque de possibilidades que se confundem, ocasionalmente, com a própria delimitação da pesquisa em termos teóricos. Aquele primeiro ano, em que geralmente os doutorandos cursam as disciplinas analisadas, é decisivo na formação da elaboração do que o investigador terá pela frente para executar. Falamos desde seu recorte do objeto de estudo, com o qual ele operará, até suas conclusóes, que o colocam em um ritual de defesa acadêmica.

A escolha por um dos paradigmas no momento de elaboração do projeto de pesquisa muitas vezes finda por ocasionar disputas epistemológicas acirradas e desnecessárias, como se tais paradigmas fossem incompatíveis. A metodologia mista deveria propor, por exemplo, a coexistência destes modos de fazer no processo de investigação, parcerias. Porém, os processos qualitativo e quantitativo, nas práticas metodológicas de nossos pesquisadores investigados, quase não aparecem como plano de diálogo inclusivo aos propósitos das teses, tampouco das disciplinas analisadas.

A pesquisa qualitativa ocorre de maneira menos unificada do que a quantitativa, embora nas ciências sociais não exista um método único de trabalho, mas sim, métodos, no plural. A suposta tentativa de unificaçáo de outra então imaginada metodologia das ciências sociais estaria fadada ao fracasso da padronização do que é plural, plástico e relativo. A eficácia 
das ciências sociais não está na unidade haja vista a diversidade de objetos que considera. De igual modo, nenhum dos paradigmas aqui tratados é análise em si. São, e apenas, instrumentos que preparam o terreno para análise porque recortam as etapas de métodos e técnicas de pesquisa. Sabemos que há potencialidades e limitações nas duas abordagens.

Frisamos a importância das condiçôes de domínio por parte dos investigadores em ambas as metodologias. Ainda que o pesquisador apoie-se mais em uma ou em outra perspectiva, ter as propriedades mínimas adequadas à leitura e compreensão de pesquisas realizadas por outrem é parte integrativa da formação do cientista social. Nenhum dos paradigmas é mais científico que outro; todavia, para exercício da ciência, a manipulação consciente e responsável de realização, leitura e análise, fazem-se necessárias para o estoque de conhecimento da profissão de investigador e/ ou docente. A partir da possibilidade de mesclas e da liberdade acadêmica/ criativa de que fazemos uso, percebemos que os paradigmas qualitativo e quantitativo, que a rigor teriam aplicação a depender diretamente do problema de pesquisa das teses, não são aplicados por esta lógica, estando o acesso às técnicas e às influências acadêmicas mais gerais na frente das tomadas de decisão metodológicas do universo dos doutorandos.

Os dados levantados até aqui são interessantes a várias interdiscursividades sobre produção acadêmica. As metodologias e suas formas de produção são partes integrantes de um processo educacional político muito mais complexo do que em geral se supóe. Estas realidades não são estanques. Ainda na década de 1990, Fábio Wanderlei Reis (1991) já criticava o ensino metodológico das ciências sociais restrito a marcos teóricos desligados dos problemas mais empíricos de pesquisa. O acompanhamento dos Programas sobre as metodologias das teses, entendemos, ultrapassa o exercício didático das disciplinas voltadas à metodologia e aos acompanhamentos de orientação, conforme visto ao longo das entrevistas realizadas.

A pesquisa de campo nos indica que muitas vezes as técnicas de pesquisa são ensinadas de forma impressionista. Cano (2012) já advertia sobre a confusão entre os termos "arte" e "pesquisa qualitativa". Ainda que arte possa se configurar com uma metáfora para localizarmos os aspectos mais criativos destas perspectivas de análise (CANO, 2012), muitos de nossos interlocutores nos relatam a necessidade de compreensão dos processos 
metodológicos de forma mais ligada a aspectos reais da rotina de investigação, especialmente quando encontramos doutorandos em Sociologia formados em graduaçóes distintas das ciências sociais.

Outro aspecto dificultoso no processo de construçáo de tese, como já suposto, é o separatismo metodológico. Não sendo este exclusivo ao conjunto de falas dos recém-doutores, posto que muitas entrevistas frisaram sobre tensôes de separatismos teóricos, materializado nas relaçóes de orientação e percurso dentro dos Programas, o separatismo entre "pesquisa qualitativa" e "pesquisa quantitativa" é refletido não apenas na oferta de disciplinas, como vimos, mas também no quão interessante estas disciplinas possam parecer aos estudantes. "É justamente o espírito atormentado das ciências sociais e a luta entre escolas ou paradigmas rivais que têm alimentado o interesse no método e intensificado as disputas em torno dele" (CANO, 2012, 94). Mais uma vez, o estímulo às disciplinas e sobre como fazê-las mais aplicáveis aos doutorandos não é aspecto desconectado das relaçôes de produção de tese mais amplas dos Programas, sobretudo, porque muitas destas disciplinas metodológicas são eletivas em alguns PPGSs. Logo, como fazer para que as metodologias sejam tema interessante e que este interesse reverbere na produção das teses? Infelizmente esta questão não será respondida nesta conclusão, considerando as limitaçôes pedagógicas e as reais intensóes de nossa hipótese; porém, localizamos as questóes mais tensas, que envolvem processos de reflexão da educação em nível doutoral, para que a questão seja enfrentada em estágio ulterior.

Por fim, corroboramos nossa hipótese apresentada nas primeiras páginas de que os problemas de pesquisa das teses de Sociologia não determinam os métodos a serem utilizados nos trabalhos, sendo tais métodos determinados pelas condições de competências técnicas e de formação dos pesquisadores e por dimensóes relacionadas a fatores relacionais entre os atores e a vida acadêmica. As disciplinas de metodologia são essenciais na formaçáo do doutor ou doutora em Sociologia e são importantes veículos de construção das teses, no que devem ser acessíveis a questóes empíricas e de formação destes atores. Entretanto, estas disciplinas isoladas não conseguem responder às necessidades desta elaboração mais complexa chamada metodologia em uma tese, sendo a metodologia fruto de um processo de formação doutoral em que relaçôes de orientação, possibilidades de acesso 
a experiências acadêmicas como as de intercâmbio, saúde mental, dentre outras, são aspectos determinantes na formação do sociólogo.

\section{Referências}

ARCOVERDE, L. et al. Número de professores afastados por transtornos em SP quase dobra em 2016 e vai a 50 mil. GloboNews. São Paulo, nov. 2017. Disponível em: https:/g1.globo.com/sp/ sao-paulo/noticia/numero-de-professores-afastados-por-transtornos-em-sp-quase-dobra-em-2016e-vai-a-50-mil.ghtml. Acesso em: 10 abr. 2019.

BARDIN, L. Análise de Conteúdo. São Paulo: Edições 70, 2011.

BARRECHEGUREN, P. La tesis doctoral es prejudicial a la salud mental”. El País, mar. 2018. Disponível em: https://elpais.com/elpais/2018/03/15/ciencia/1521113964_993420.html. Acesso em: 10 abr. 2019.

CANO, I. Nas trincheiras do método: o ensino da metodologia das ciências sociais no Brasil. Revista Sociologias, Porto Alegre, ano 14, n. 31, p. 94-119, 2012.

ERRANDONEA, A. Algunas reflexiones en defensa de la construcción empírica del conocimiento sociológico. In: ERRANDONEA, A. La producción sociológica en Buenos Aires en la postdictadura. Instituto Gino Germani, Facultad de Ciencias Sociales, Universidad de Buenos Aires, Argentina, [s. d.]. p. 9.

FERREIRA, L.; FURTADO, F.; SILVEIRA, T. Relação orientador-orientando: o conhecimento multiplicador. Acta Cirúrgica Brasileira, São Paulo, v. 24, n. 3, p. 170-172, maio/jun. 2009.

FILHO, G.; MARTINS, G. Relaçôes orientador-orientando e suas influências na elaboração de teses e dissertaçôes. Revista de Administraçáo de Empresas, São Paulo, v. 46, p. 99-109, nov./dec. 2006.

MACHADO, D.; TONIN, J.; CLEMENTE, A. Orientador e orientando ideais: similaridades e dissimilaridades na percepção de professores e alunos. Revista Contemporânea de Contabilidade, Florianópolis, v. 15, n. 35, p. 3247, abr./jun. 2018.

MELO, M.; BERNARDO, A. C.; GOMES, S. As teses da área de Sociologia do Brasil: padróes e inflexôes temáticas e metodológicas. Revista Brasileira de Sociologia, v. 6, n. 13, p. 58-75, 2018.

MILLS, W. A imaginação sociológica. São Paulo: Zahar Editor, 1975.

NOBREGA, M. H. da. Orientandos e Orientadores no Século XXI: desafios da pós-graduação. Educação e Realidade, v. 43, n. 3, p. 1055-1076, 2018.

OLIVEIRA, R. Depressão na universidade: como a pressão acadêmica afeta a saúde mental. Instituto Geledés, 29 jun. 2018. Disponível em: https://www.geledes.org.br/depressao-nauniversidade-como-pressao-academica-afeta-saude-mental. Acesso em: 10 abr. 2019.

REIS, F. W. O Tabelão e a Lupa: teoria, método generalizante e ideografia no contexto brasileiro.

Revista Brasileira de Ciências Sociais, v. 16, n. 6, p. 27-42, jul. 1991. 
RODRIGUES JR., J.; FLEITH, D.; ALVES, K. A Dissertação de Mestrado: um Estudo sobre as Interaçóes entre o Orientador e o Orientando com Base em Incidentes Críticos. Revista Brasileira de Pedagogia, Brasília, v. 74, n. 177, p. 437-463, maio/ago. 1993.

ROJAS, G. G.; MARTÍNEZ, S. L. Aproximaciones a la caracterización de la producción sociológica de Buenos Aires (1984-1996). In: En torno de las metodologías: abordajes cualitativos y cuantitativos. Buenos Aires: Editorial Proa XXI, 2003. p. 25-37.

VIANA, C.; VEIGA, I. O diálogo acadêmico entre orientadores e orientandos. Educaçáo, Porto Alegre, v. 33, n. 3, p. 222-226, set./dez. 2010.

\section{The methodologies of newly-doctors of post-graduation programs in sociology in Brazil: from disciplines to theses}

\section{Abstract}

This paper analyzes the sociology doctors in Brazilian Graduate Studies and investigates the hypothesis that the research problems content in the sociology thesis are not determinant for the methods used in the works, in the methodology of the theses. Our hypothesis consider as more important than the sociologies problems and issues the technical skills the PhD students have about different kinds of methodology. The present article seeks to observe the attention given to the methodological aspect of thesis work, examining the perception and interest that doctors have in relation to the various methodological ways of research. We present article has a documentary analysis about the methodology courses in PhDs graduate studies and a content analysis carried out from 35 interviews with recent sociology PhDs. It also examines the emphasis the theses placed on methodological considering aspects as institutional relations and academic exchanges.

Keywords: Sociological theses. Graduate studies. Methodology.

Recebido em: 29/11/2018

Aprovado em: 03/04/2019 